\title{
DISCUSIONES
}

CRítICA, Revista Hispanoamericana de Filosofia

Vol. XXI, No. 63 (diciembre 1989): 75-81

\section{WARD ON DAVIDSON'S REFUTATION OF SCEPTICISM}

\author{
GUILLERMO HURTADO \\ Magdalen College, Oxford/ \\ Instituto de Investigaciones Filosóficas, UNAM
}

It seems to me that Andrew Ward's recent examination of Davidson's Omniscient Interpreter argument ${ }^{1}$ has failed to elucidate it correctly. Ward's problems originate from the fact that he did not follow Davidson's argument au pied de la lettre. In "The Method of Truth in Metaphysics" Davidson presents his argument in this way:

We do not need to be omniscient to interpret, but there is nothing absurd in the idea of an omniscient interpreter; he attributes beliefs to others, and interprets their speech on the basis of his own beliefs, just as the rest of us do. Since he does this as the rest of us do, he perforce finds as much agreement as is needed to make sense of his attributions and interpretations; and in this case, of course, what is agreed is by hypothesis true. But now it is plain why massive error about the world is simply unintelligible, for to suppose it intelligible is to suppose there could be an interpreter (the omniscient one) who correctly interpreted someone else as being massively mistaken, and this we have shown to be impossible. ${ }^{2}$

Ward reinterprets the argument in the following way:

(1) A language user having all and only true beliefs is intelligible.

1 Crítica, Vol. XXI/No. 61/México, abril 1989.

${ }^{2}$ Davidson, Inquiries into Truth and Interpretation, OxTord, 1984. p. 201. 
(2) If we cannot find a way to interpret the utterances and other behavior of a creature... we have not reason to count that creature... as saying anything.

(3) From (1) and (2) it follows that the intelligibility of a language user having all and only true beliefs requires that we are, in principle able to interpret $h i s$ language.

(4) A necessary condition for interpretation is that the interpreter and the creature being interpreted share a coherent system of beliefs.

(5) Thus if (3) is the case, it must because we share a coherent system of true beliefs with that $\mathrm{OI}$ and hence scepticism has been undercut.

Ward's reconstruction of Davidson's argument not only fails to capture Davidson's main point, but is also unsound, for (3) does not follow from (1) and (2).

If we read Davidson's presentation of the argument carefully, we find that he affirms that the Omniscient Interpreter (hereafter OI) can interpret $u s$ and not - as Ward suggests - that we can interpret him. Negligible detail? Not at all. There is a huge difference between both claims, for there is no guarantee of symmetry in the radical interpretation process. Even if we grant that an $\mathrm{OI}$ is intelligible and we also suppose that he can interpret us, it does not follow that we can also interpret $\mathrm{him}$.

Imagine the case - described by Strawson in Individuals of a community of intelligent beings that has a conceptual scheme based merely on sounds. Imagine also that we could hear the same sounds as they do. If that were the case then we could, at least in principle, interpret them and hence communicate with them in their language. However, it seems to me that they could not interpret our language, for they would not share with us the massive amount of information we receive through the rest of our senses and hence they could not form the same beliefs. The divergence between both of us would be so big 
that they would not be able to communicate with us in our language. To give another example; imagine an intelligent machine specialized in chess. I can play the game with the machine, because both of us know the rules and have - so to speakthe same beliefs about what is a good move, what is the goal of the game, etc. There is even a sense in which we could say that the machine interprets my game. However, despite the fact that there is communication between the two of us, it does not follow that the machine could interpret my everyday language. The same - I will argue - could happen between us and an OI. He might be able to interpret us, but we might not have all the information and the intelligence required to interpret him.

One must be fully aware of the significance of Davidson's assumption of the intelligibility of an Omniscient being. Such a being has all and every single one of the true beliefs that can possibly be held. It seems to me that if we want to make any sense of a being knowing everything he has to be virtually omnipresent and eternal. The OI must be in possession of all the information required in order to have all the true beliefs that can be held. But is this really intelligible? It seems to me that the notion of an OI, like the Russellian notion of a perfect language (i.e., a language that perfectly depicts the world) is a rationalist dream that assumes a great deal about the nature and conditions of possibility of representation. Even if we accept that truth is objective and that the world is not the result of our making, we might still not agree on the possibility of a pure representation (mental or linguistic) of the world. An assumption behind the notion of an OI is that he could see the world such as it is, without any deformation or limitation produced by his own subjectivity. However, one might maintain the (non-sceptical) thesis that thought is necessarily perspecti$v a l, i$.e. that it is necessarily framed within the context of the spatio-temporal position of a particular body. If perspectivism is right, then there are innumerable true beliefs that are out of the OI's reach. For example, he might not be able to hold the 
same belief as I do when I think that I am standing here, even if he entertained a true belief with the content like he is standing there.

These questions, no matter how pressing they might be, should not worry us too much now. I am convinced that Davidson's hypothesis of the Omniscient Being is not essential to the basic point that he wants to make; namely, that there is a necessary connection between our understanding of meanings and our apprehension of truths. However, I would like to make a last point about the OI. I cannot imagine any other possible candidate for this role than God. This again shows how wrong it is to see Davidson's argument as Wand does. God's mind might be inscrutable and quite beyond our limited intellect. He might communicate with us, however, we might not be able to interpret him in the same way that we interpret, say, Hopi Indians. God's linguistic behaviour - if there is such a thing - is perhaps not recognisable as such unless he, with all his grace, allows it. But then, since the idea of a distant God that does not want to reveal anything is perfectly intelligible, the intelligibility of an OI does not guarantee, as Ward maintains, the assumption that such an OI could be interpreted by $u s$.

The problems with Ward's reinterpretation do not end here. We can distinguish between:

(A) someone that has all and every single one of the true beliefs that can possibly be held. (B) someone that has no false beliefs.

As it must be obvious a real OI responds to (A)'s description and not to (B)'s. However on Ward's reading of the argument it does not matter whether it is one or the other. If we can interpret someone who is not omniscent, but has no false beliefs, then it follows that most of our beliefs are also true and hence that the sceptic is wrong. Compared to the OI, someone that has no false beliefs but still does not know everything is rather ignorant. But the point of the sceptic is not that we are ignorant, but that we are mistaken. It seems to me, however, that the fact that Ward's 
reading of the argument tolerates this ambiguity is not a good sign. It is (perhaps) a platitude to say that there is only one reality. However it is not a platitude to say that all systems of beliefs share the same stock of objects and concepts. From the fact that all the beliefs held by a speaker are true, it does not necessarily follow that he could interpret another speaker that has only true beliefs. Why? Because the true beliefs held by speaker-l can be about completely different things from those held by speaker-2. For interpretation to be possible there must be a coincidence of the same beliefs - be they true or false.

This example shows that from the intelligibility of a speaker who has no false beliefs, it does not follow that we can interpret him or he us, for we could imagine a speaker of a very alien language whose beliefs have a radically different subject matter. But, as we have seen above, it also does not follow from the fact that we can interpret someone that has no false beliefs that we are not grossly mistaken about the world, for it might be the case that such a speaker has only beliefs about chess and nothing else.

Ward's way out could be to say that a speaker who has only true beliefs is only intelligible if we can conceive him as speaking our same language and as sharing our same system of beliefs. But this would be a trick. Ward could not assume this unless he gave us an argument that showed the uninteligibility of a speaker who has no false beliefs but speaks an untranslatable language. In "On the Very Idea of a Conceptual Scheme" Davidson offered an argument that may or may not be sound against the idea of an untraslatable language. However that is another argument and if we do not want to get trapped in a potentially dangerous circle, we should not bring this into Davidson's argument against the sceptic. These considerations show that Ward's way of looking at Davidson's argument is not on the right track.

In order to understand Davidson's argument we have to abandon Ward's reconstruction of it and consider the intelligibility 
of a real Omniscient Being interpreting our language behaviour. The rest of this paper is devoted to showing what in my opinion is the main point of Davidson's argument.

We can agree that if $X$ is a language translatable by the OI, then most of the beliefs of the speakers of $X$ are true. The problem is that this is not the same as saying that if $X$ is a language then most of the beliefs of its speakers are true. We need to show that all languages can be, at least in principle, translated by the OI.

The clue lies in considering the nature a language that cannot be translated by the OI. Davidson says:

... imagine for a moment an interpreter who is omniscent about the world, and about what does and would cause a speaker to assent to any sentence of his (potentially unlimited) repertoire. The omniscient speaker using the same method as the fallible interpreter, finds the fallible speaker largely consistent and correct. ${ }^{3}$

We might ask why the OI can, at least in principle, interpret any language? Why is the possibility of a language that cannot be translated by the OI dismised a priori? The reason for this is that the OI has all the relevant information in order to translate any language, namely, all that causes or may cause a speaker to assent to any sentence of his language. The way in which OI knows what we mean is not - as Wittgenstein aptly remarked - by opening our heads or reading our minds. The OI, despite all his omniscience, has to go to the fields and interpret a speaker on the basis of his assent or dissent of certain sentences in certain situations. The only difference between him and a fallible interpreter is that he knows all the truths of the world, but these truths - and this is the crucial point-are all that is necessary to know in order to translate a language. If with all this information some apparent linguistic behaviour can still not be interpreted, it is because it was, after all, not

3 Davidson, "A Coherence Theory of Truth and Knowledge" in E. Le Pore (ed.), Truth and Interpretation, Basil Blackwell, 1986. p. 317. 
linguistic behaviour. This is the hidden Quinean premiss of Davidson's argument: the meaning of any sentence is fully determined (or indetermined) by knowing what causes or would cause a speaker to assent to it. This is why the OI uses the same method as the fallible interpreter and finds perforce as much agreement as is needed to make sense of his attributions.

The core of Davidson's trascendental argument (to summarize it in words that he would never use) is this: a condition of possibility of meaningfulness is truthfulness. If something is a language (i.e. a vehicle of meaning), it must depict the world in an efficient way (though not, of course, in a perfect way). Otherwise it is not a language, but an attempt of language. This is what renders so incomprehensible the idea of a language speaker who is grossly mistaken about the world. If a language is an instrument to depict the world, then what kind of linguistic activity could someone have who is totally ignorant about how the world really is? For belief to be possible, it requires a background of success. As Davidson's puts it: "Too much mistake simply blurs the focus". 4

If meaning is grounded on the behavioural response of speakers towards certain stimuli coming from their common environment, then the OI can in principle - and Ward is right in stressing this point - interpret any language. We can now understand why Davidson affirms with such conviction that:

What makes interpretation possible is that we can dismiss a priori the chance of massive error. A theory of interpretation cannot be correct that makes a man assent to very many false sentences: it must generally be the case that a sentence is true when a speaker hold it to be. ${ }^{5}$

Recibido- 9 noviembre 1989

4 Davidson, Inquiries into Truth and Interpretation, p. 168.

5 ibid., p. 169. 